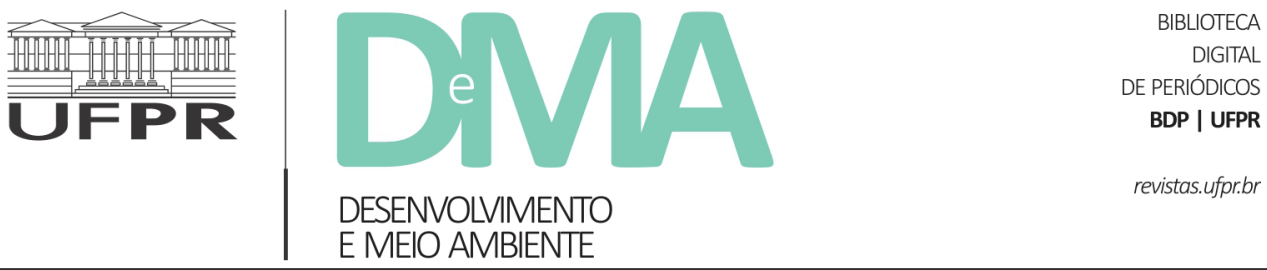

\title{
Panorama da seca plurianual 2012-2018 no semiárido brasileiro: impactos hidrológicos, agrícolas e medidas de convivência
}

\section{Multiannual drought overview (2012 - 2018) in the Brazilian semiarid region: hydrological and agricultural impacts and coexistence initiatives} \author{
Costa BRAGA ${ }^{2}$ \\ ${ }^{1}$ Universidade Federal de Campina Grande (UFCG), Campina Grande, PB, Brasil. \\ ${ }^{2}$ Instituto Federal de Educação, Ciência e Tecnologia da Paraíba (IFPB), Guarabira, PB, Brasil. \\ *E-mail de contato: yascaramaiaa@gmail.com
}

Yáscara Maia Araújo de BRITO ${ }^{1 *}$, Higor Costa de BRITO ${ }^{1}$, Iana Alexandra Alves RUFINO ${ }^{1}$, Cybelle Frazão

Artigo recebido em 23 de junho de 2020, versão final aceita em 7 de junho de 2021, publicado em 17 de dezembro de 2021.

RESUMO: O Semiárido Brasileiro compreende a região mais seca do Brasil. Embora diversas políticas públicas sejam implementadas para mitigação do fenômeno, os impactos associados à escassez hídrica ainda são bastante severos. Diante dessa justificativa, o artigo objetiva analisar a gravidade, duração e extensão espacial da seca plurianual 2012-2018, compará-la ao ciclo de recuperação não seco de 2018-2020, identificando impactos e relações intrínsecas com as decisões tomadas pelos gestores em diferentes níveis. Para esse fim, são utilizadas plataformas que monitoram o andamento do evento, seus impactos e as medidas de convivência adotadas para atenuar tais efeitos. O Monitor de secas indica que o pico de maior severidade acontece entre o final de 2016 e início do ano seguinte. A seca excepcional, que é a tipologia mais intensa, chega a atingir mais de $85 \%$ do território semiárido. Os impactos esperados para esse nível indicam escassez de água generalizada nos reservatórios. Essa perspectiva confirma-se quando observados dados do portal Olho N'água de variação do volume armazenado. No mesmo período, a reserva hídrica dos açudes do semiárido cearense, potiguar, paraibano e pernambucano atingem mínimosníveis, com registros que chegam ao volume morto. Para mitigar a sucessão de impactos ocasionados, tomadores de decisão nas escalas de atuação municipal, estadual e regional utilizam-se de medidas estruturais, entre as quais estão a construção de açudes, cisternas, perfuração de poços e distribuição de água por carros-pipa. Em contrapartida, raramente atentam-se à elaboração de planos de preparação para as frequentes secas. Apesar do avanço nos paradigmas de gestão, as primeiras medidas adotadas no século XIX, que consistiam na construção de infraestrutura hídrica, ainda são empregadas em 
larga escala. As políticas públicas voltam-se a mitigar efeitos já instaurados, ao invés de priorizar a gestão proativa, a partir da criação de gatilhos estabelecidos sob perspectivas de previsão e monitoramento do evento.

Palavras-chave: intensidades de seca; escassez hídrica; plataformas de monitoramento; medidas estruturais.

ABSTRACT: The Brazilian Semiarid comprises the driest region in Brazil. Although several public policies are implemented to mitigate the phenomenon, the impacts associated with water scarcity are still quite severe. Given this justification, the article aims to analyze the severity, duration, and spatial extent of the multi-annual drought 2012 - 2018 and compare it to the non-dry recovery cycle of 2018 - 2020, identifying impacts and intrinsic relationships with the decisions made by managers at different levels. For this purpose, platforms are used to monitor the event's progress, impacts, and coexistence measures to mitigate such effects. The Drought Monitor indicates that the peak of greatest severity occurs between 2016 and the beginning of the following year. The exceptional drought, which is the most intense typology, reaches more than $85 \%$ of the semiarid territory. The expected impacts at this level indicate widespread water scarcity in the reservoirs. This perspective is confirmed when observing data from the Olho N'água portal of variation of the stored volume. In the same period, the water reserve of the reservoirs of the semiarid Cearense, Potiguar, Paraibano, and Pernambucano reached minimum levels, with records reaching dead volume. To mitigate the succession of impacts caused, decision-makers at the municipal, state, and regional scales use structural measures, among which is the construction of dams, cisterns, well drilling, and water distribution by water trucks. On the other hand, they rarely pay attention to preparing plans for the frequent droughts. Despite advances in management paradigms, the first measures adopted in the 19th century, which consisted of building water infrastructure, are still employed on a large scale. Public policies aim to mitigate already established effects instead of prioritizing proactive management, based on the creation of established triggers from the perspective of forecasting and monitoring the event.

Keywords: drought intensities; water scarcity; monitoring platforms; structural measures.

\section{Introdução}

As regiões áridas e semiáridas são regiões atingidas por diferentes eventos extremos, entretanto, os de maior frequência são as secas. Estas consistem em déficits hídricos naturais e recorrentes, responsáveis por causar desequilíbrios meteorológicos, hidrológicos, agrícolas ou socioeconômicos ao meio ambiente e à sociedade. Como consequência, tem-se impactos de diferentes magnitudes que geram conflitos pelo uso da água e penalizam, sobretudo, a segurança hídrica alimentar e energética das populações mais vulneráveis (Wilhite \& Glantz, 1985; Mishra \& Singh, 2010; AMS, 2013; Marengo \& Bernasconi, 2015; Brito et al., 2018).
As secas configuram-se como um desastre natural quando afetam regiões densamente povoadas, como o Semiárido Brasileiro (SAB), que ampara uma população de quase 30 milhões de habitantes, a qual tem baixa capacidade de adaptação para lidar com a gravidade dos danos gerados (Alvalá et al., 2019; Cunha et al., 2019). Entretanto os danos causados pelos eventos de seca nessa região datam desde o século XVI, quando era ainda pouco povoada por indígenas. Os registros de seca são recorrentes ao longo dos séculos, entre os quais destaca-se o evento de 1721-1727, a segunda maior seca plurianual já registrada (Campos, 2014; Campos, 2015). Esta fica atrás apenas da ocorrência que atinge não só a região Nordeste, mas todo o Brasil, com início 
em 2012 e estendendo-se até 2018 (Maisonnave \& Prado, 2018).

De acordo com Wilhite et al. (2000), existem duas tipologias de gestão de secas: o ciclo proativo (também chamado de gestão de risco) e o ciclo reativo ou gestão de crise. Este tem como fundamento a recuperação de áreas já atingidas pelo evento de seca, enquanto aquele baseia-se na proteção da região ao enfrentamento do fenômeno. Em uma de suas publicações mais recentes, Wilhite (2019, p. 1) afirma que "A resposta à seca por governos e outras organizações em todo o mundo tem sido reativa mal coordenada, ineficaz e prematura”. No Brasil, em especial no SAB, não é diferente. Tomam-se medidas após a ocorrência da seca (Magalhães, 2016). Contudo, com o advento do século XXI e a ampla disseminação dos sistemas de informação abertos e gratuitos, as ferramentas de planejamento contam com novas abordagens, sobretudo no campo do monitoramento.

O Monitor de Secas do Brasil (MSB), uma iniciativa da Agência Nacional de Águas (ANA) e tantos outros parceiros, em meados de 2014, lançam uma plataforma que permite acompanhar a intensidade, extensão espacial e possíveis impactos da seca, mensalmente, para toda a região Nordeste (Martins et al., 2015). Em meio à maior seca já registrada, advém uma forma de monitorar o avanço ou retrocesso de um desastre natural, que causa tantos impactos negativos aos nordestinos há séculos, dando início a uma mudança no âmbito de preparação para o fenômeno.

A escassez de água resultante das secas desencadeia impactos diversos à população residente na região. No Semiárido, o abastecimento aos múltiplos usos advém, predominantemente, de reservatórios superficiais. A região apresenta, entre outras características de relevância, uma grande variabilidade climática, com irregularidades espaço-temporais na precipitação e elevadas taxas de evapotranspiração, as quais manifestam-se em ciclos plurianuais de escassez hídrica intercalados com períodos chuvosos intermitentes (Magalhães, 2016; Brito et al., 2018). Consoante Nunes et al. (2016), tais particularidades geram um cenário de incerteza, no que se refere ao abastecimento de água na região, originando diversos conflitos pelo uso a partir de discrepâncias entre a oferta e a demanda hídrica.

Segundo Cunha et al. (2019), o setor agrícola é precursor nos impactos ocasionados pela seca. A umidade do solo decai e, no SAB, as atividades econômicas giram em torno da agricultura de subsistência, amplamente praticada na região; das pastagens de rebanhos bovinos; criação de caprinos e sua produção de leite; além da criação de aves. Todas são desempenhadas por pequenos agricultores como fonte de renda. Essa população rural é a mais vulnerável socioeconomicamente aos eventos de seca e obtém água mediante pequenos reservatórios construídos na propriedade (Campos, 2015). Quando estes são ausentes, o abastecimento se dá por meio da construção de cisternas que captam água de chuva, entre as quais estão as construídas pelo Programa Um Milhão de Cisternas (P1MC), ou de carros-pipa e perfuração de poços.

De acordo com o Plano Nacional de Segurança Hídrica (PNSH) da ANA (2019, p. 66), a reversão de um quadro de insegurança depende, além de uma infraestrutura hídrica robusta e uma adequada gestão dos recursos, do "conhecimento aprofundado da vulnerabilidade e da exposição do ambiente diante de algum evento, visando à proposição de ações dirigidas ao aumento da resiliência da área". 
Martins et al. (2016) apontam que, embora exista uma série de plataformas digitais com informações úteis sobre secas, estas ainda não são utilizadas de forma eficiente na gestão do fenômeno. Há a necessidade de criação de um processo participativo que englobe instituições nos níveis local, estadual e federal que respondam previamente às pressões e impactos originados.

Diante do exposto, o artigo objetiva analisar o ciclo plurianual de secas (2012-2018) e compará-lo ao ciclo de recuperação não seco de 2018-2020, no SAB. Inicialmente tem-se a caracterização da intensidade, duração e extensão espacial do fenômeno, por meio do MSB. Subsequentemente são avaliadas as variações do volume armazenado de água nos reservatórios superficiais de abastecimento da região, a fim de observar quais são os períodos mais críticos e confrontá-los com os impactos nas atividades agrícolas. Por fim, são pautadas quais as medidas estruturais e não estruturais empregadas pelos municípios do $\mathrm{SAB}$, na convivência com a seca histórica mais intensa já registrada, a fim de dispor respostas que auxiliem os gestores públicos na tomada de decisão quanto às providências estratégicas e táticas necessárias para lidar com o evento de seca mais duradouro já registrado na região em estudo.

\section{Metodologia}

\section{1. Área de estudo}

O SAB compreende 1.272 municípios distribuídos ao longo de 10 Unidades da Federação (UFs) que são todos os nove estados pertentes à região Nordeste-Alagoas (AL), Bahia (BA), Ceará (CE),
Maranhão (MA), Paraíba (PB), Pernambuco (PE), Piauí (PI), Rio Grande do Norte (RN) e Sergipe (SE), além de Minas Gerais (MG), no Sudeste do país (SUDENE, 2017), conforme a Figura 1.

A região compreende uma área de 1.128.697 $\mathrm{km}^{2}$, em que mais de $89 \%$ situa-se no Nordeste (IBGE, 2018). De acordo com a Superintendência do Desenvolvimento do Nordeste (SUDENE, 2017), órgão deliberativo que atua no $S A B$, em sua Resolução $n^{\circ} 107 / 2017$ estabelece, no Art, $1^{\circ}$, os seguintes critérios para a inclusão de um município na delimitação:

(i) precipitação média anual igual ou inferior a $800 \mathrm{~mm}$;

(ii) Índice de aridez de Thorntwaite igual ou inferior a 0,50 ;

(iii) Déficit hídrico diário igual ou superior a $60 \%$ para todos os dias do ano.

O semiárido enquadra-se como a área mais seca do país. As precipitações anuais, que se concentram entre fevereiro e maio, variam entre $400 \mathrm{e}$ $800 \mathrm{~mm}$. Em contrapartida, as taxas de evaporação atingem mais de $2.000 \mathrm{~mm}$ por ano. Os solos tipicamente rasos, sob rochas cristalinas, não propiciam o provimento de recarga hídrica subterrânea, o que acarreta a intermitência dos cursos d'água superficiais (Campos, 2015; Magalhães, 2016).

A Caatinga, bioma exclusivamente brasileiro, ocupa a maior parte do SAB. A produção agropecuária destaca-se com a criação de bovinos, caprinos, ovinos e suínos. Os rebanhos são cultivados de forma extensiva (soltos), intensiva (confinados) ou semi-intensiva (parte do dia soltos, parte confinados), predominando a primeira. Quanto à produção agrícola, esta desenvolve-se na forma da agricultura 
de sequeiro - ocorre nos meses chuvosos, a agri- irrigada - que depende da construção de um sistema cultura de vazante - plantada à margem dos corpos que obtenha a água de um reservatório (Silva et d'água quando estes vão secando, e a agricultura al., 2013). Essa última é pouco aplicada na região.

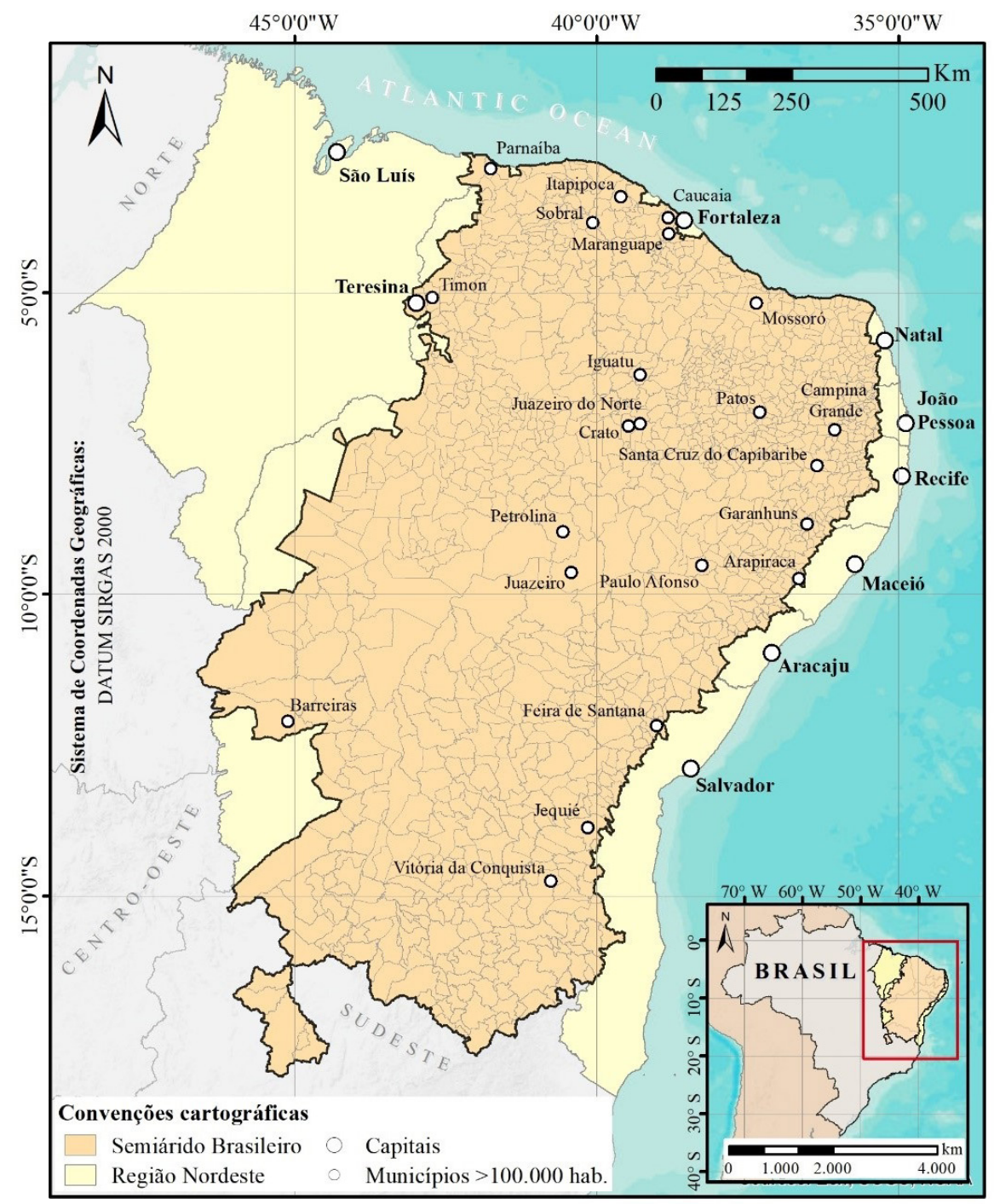

FIGURA 1- Localização do semiárido brasileiro com identificação dos municípios da Região Nordeste que apresentam mais de 100 mil habitantes. FONTE: Elaborada a partir de IBGE (2018). 


\subsection{Caracterização da seca e seus impactos}

A metodologia apresentada baseia-se no estudo desenvolvido por Dantas et al. (2020), que utilizam o MSB (ANA, 2020) para monitorar o comportamento espacial das secas, por meio da espacialização dos mapas mensais de 2015 e 2016 para o Nordeste. Em seguida, faz uso dos dados da plataforma Olho N'água (INSA, 2020) para analisar o impacto das secas no volume de água armazenado nos maiores açudes da Bacia do Alto Rio Paraíba (Epitácio Pessoa, Cordeiro, Poções e Sumé).

É importante ressaltar que o portal Olho N'água, assim como outras aplicações de software do INSA, está desativado temporariamente (desde meados de 2021), mas isso não compromete o desenvolvimento da proposta do artigo, uma vez que há outras fontes que disponibilizam essas mesmas informações. A obtenção de dados que possibilitem o acompanhamento do volume de água nos reservatórios da região semiárida pode ser realizada também por meio do Sistema de Acompanhamento de Reservatórios (SAR) da Agência Nacional de Águas e Saneamento Básico (ANA, 2021), que se divide em três módulo, sendo um destes referente ao Nordeste e Semiárido brasileiros.

Diante disso, o artigo aqui desenvolvido estrutura-se a partir de uma análise da última seca plurianual registrada no SAB (2012-2018). Toda a análise é realizada a partir de informações secundárias obtidas de portais nacionais, as quais permitem traçar um panorama do evento de seca citado. $\mathrm{O}$ estudo se divide em cinco etapas de execução, conforme aponta a Figura 2. Inicialmente a seca é caracterizada quando à sua intensidade $\mathrm{e}$ extensão territorial com base no MSB (Etapa 1), da Agência Nacional de Águas (ANA), que utiliza indicadores meteorológicos e hidrológicos para a sua composição.

A primeira etapa corresponde à caracterização da seca sob aspectos de intensidade, duração e extensão espacial para todo o território do Semiárido. Os dados são mensais e obtidos do Monitor de Secas do Brasil, para o período de julho de 2014 a março de 2020, o que totaliza 69 meses. O procedimento consiste na utilização dos arquivos vetoriais (shapefiles) mensais do MSB que classificam as secas em cinco diferentes intensidades (Tabela 1) que são denominadas por ordem crescente de gravidade: seca fraca, moderada, grave, extrema e excepcional.

O MSB originou-se a partir de uma parceria internacional entre o Banco Mundial, o National Drought Mitigation Center (NDMC) dos Estados Unidos - e a Comisión Nacional Del Agua (CONAGUA) do México. Todos contam com uma ampla e precursora experiência no monitoramento de secas que, em combinação com órgãos federais, estaduais e municipais brasileiros criaram, em meados de 2014, o Monitor de Secas Brasileiro (Martins et al., 2015).

A cada tipologia de seca são associados possíveis impactos esperados para o abastecimento e para a agricultura (Tabela 1). Esses impactos baseiam-se em Svoboda et al. (2002) e são descrições de possíveis impactos utilizados pelo U.S. Drought Monitor (USDM) dos Estados Unidos e na concepção do Monitor de Secas Brasileiro.

Os mapas de intensidades de seca são então incorporados a um Sistema de Informações Geográfica, através do software ArcGIS Desktop 10.7 (ESRI, 2019). para o processamento. Para cada mês, obtém-se a extensão territorial categorizada para cada uma das cinco tipologias de seca, a fim 


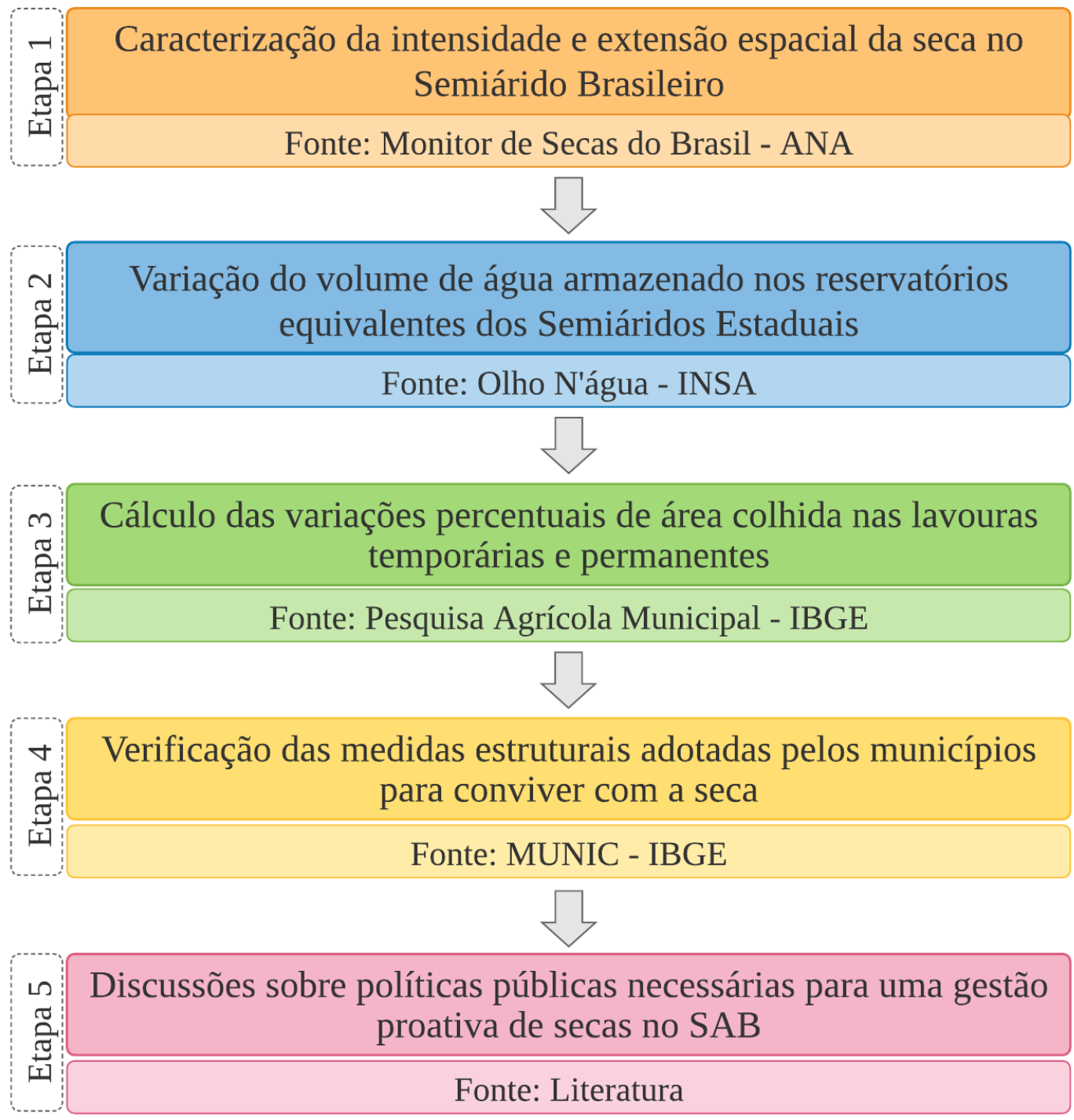

FIGURA 2 - Enumeração das cinco etapas metodológicas percorridas para traçar o panorama da seca plurianual 2012-2018, no Semiárido brasileiro, com a citação da respectiva fonte de obtenção dos dados.

FONTE: Elaboração própria. 
de originar um gráfico tabular de áreas percentuais que aponte, ao longo do período sob análise, como se dá a evolução temporal do fenômeno plurianual no SAB. Com base no diagrama, atenta-se ainda ao intervalo de maior severidade do evento, que corresponde ao maior percentual de área sob condição de seca excepcional (tipo de maior severidade).

A segunda etapa, por sua vez, apresenta uma perspectiva hidrológica do volume armazenado de água nos reservatórios equivalentes estaduais do SAB, a partir do portal Olho N'água (Etapa 2), do Instituto Nacional do Semiárido (INSA, 2020). O impacto da seca é averiguado sob o volume de água armazenado nos reservatórios superficiais. A análise é realizada no Microsoft Excel 2019 e tem como entrada os dados obtidos no portal Olho N'água, para o intervalo de janeiro/2012 a abril/2020. O MSB não permite observar o comportamento da seca desde 2012, pois a plataforma só dispõe informações de meados de 2014 em diante. Apesar de, em 2019/2020, o SAB não registrar seca, evidencia-se a utilidade de examinar como a região comporta-se no decorrer dessa dinâmica (quando não há seca).
São traçadas séries de dados que permitem acompanhar a evolução da quantidade de água armazenada para abastecimento, ao longo dos anos em questão. Nessa etapa, o Semiárido é subdivido conforme os recortes geográficos estaduais, o que permite apurar individualmente as condições de cada unidade federativa. Todo o volume de água disponível em cada divisão do SAB é acumulado e disposto em gráficos que permitem examinar a dinâmica no decurso, viabilizando a definição de gatilhos para os usos da água.

Posteriormente são calculadas as variações percentuais referentes à área colhida dos produtos de lavouras temporárias e permanentes (Etapa 3), com base na Pesquisa Agrícola Municipal (PAM) do IBGE (2019). O cálculo baseia-se na área colhida do ano anterior, para aferir se houve variação positiva ou negativa de rendimento no ano seguinte. As operações utilizam o Microsoft Excel 2019 como ferramenta e partem do ano de 2011, com base no ano de 2010 (ano chuvoso), indo até 2018. Dessa forma, inicia-se a série de dados em 2010, com o intuito de averiguar a produção em anos não secos

TABELA 1 - Categorias de seca e os respectivos possíveis impactos esperados para cada tipologia do Monitor de Secas do Brasil.

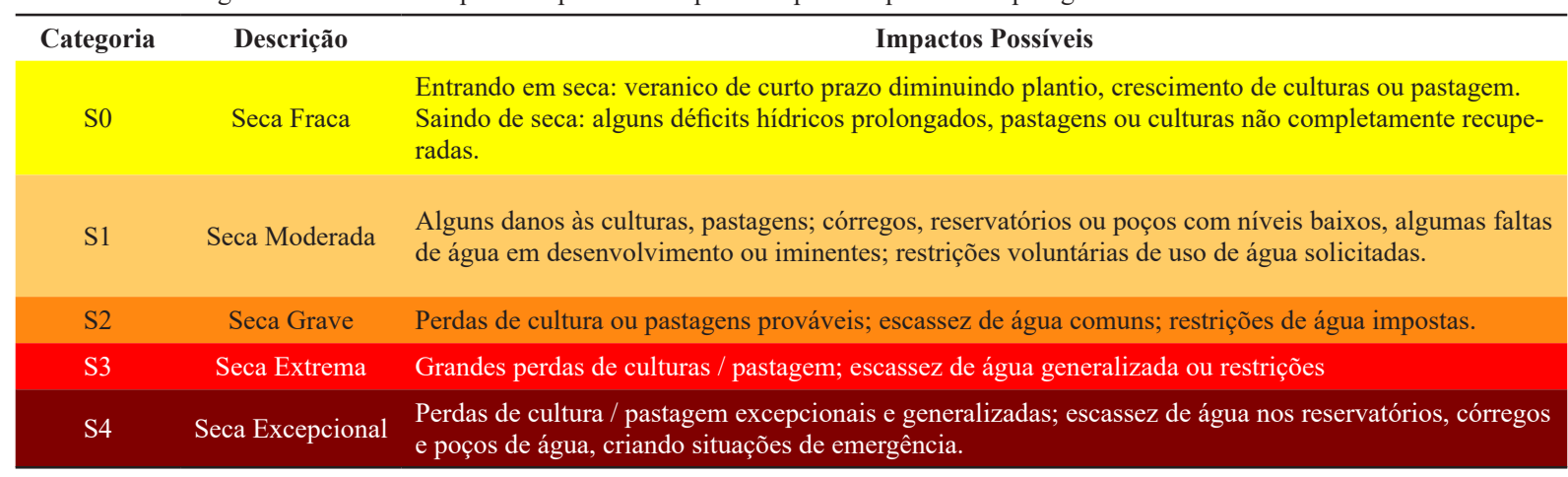

FONTE: Svoboda et al. (2002), ANA (2020), NDMC (2020). 
para, assim, delinear o comportamento dos anos secos seguintes. As informações da PAM são obtidas na escala municipal anual, em hectares, e agregadas por estado que é componente do $\mathrm{SAB}$, com o intuito de computar as variações percentuais da produção.

Já a etapa 4 permite traçar um aparato de quais medidas estruturais são utilizadas pelos municípios na convivência com as secas recorrentes. As ações compreendem a construção de açudes, a perfuração de poços para obtenção de água subterrânea, a distribuição de água por meio de carros-pipa e se a localidade apresenta algum tipo de plano de convivência ou preparação para a seca. Os dados são obtidos a partir da Pesquisa de Informações Básicas Municipais (MUNIC), também do IBGE (2017), e corresponde ao quadriênio de 2013 a 2016. Em suma, essas informações são espacializadas com o auxílio do SIG para melhor interpretá-las.

A diferença entre os períodos de dados utilizados para cada plataforma deve-se à disponibilidade de dados, além de início de operação efetiva. Neste trabalho, percebe-se que analisar anos chuvosos próximos a longos períodos de estiagem (imediatamente anteriores ou posteriores) ajuda na compreensão e identificação dos impactos. O Monitor de Secas só dispõe de dados a partir de 2014 (2014 a 2018 foram anos secos, enquanto 2019 e 2020 são considerados anos chuvosos), a pesquisa MUNIC do IBGE dispõe de dados entre 2013 e 2016 (todos os anos inserido no período seco), enquanto o portal Olho N'água evidencia dados a partir de 2012 (início da seca plurianual estudada).

Na etapa 1, esses dados foram utilizados com o intuito de evidenciar a intensidade e a extensão espacial da seca no SAB, entre 2014 e 2018 , e, em contrapartida, expressar como essas características mudam em anos não secos (2019 e início de 2020); na etapa 2, a análise foca no acompanhamento da variação de volume de água dos reservatórios equivalentes dos Semiáridos Estaduais; assim como, na etapa 3, os dados utilizados expõem a redução ou aumento da produção agrícola para anos anteriores a 2012 - anos úmidos-, e assim demonstrar se a seca influenciou na agricultura.

A última etapa do estudo (Etapa 5) permite traçar discussões referentes às políticas públicas focadas em uma gestão proativa e não reativa, como é predominantemente praticado. Wilhite et al. (2014) apontam que existem três tipos de políticas de seca que são utilizadas para a gestão do fenômeno. As discussões em torno dessa etapa permitem definir qual a tipologia de gestão utilizada pelo $\mathrm{SAB}$, se essa é a tipologia mais eficaz e, em caso negativo, apontar qual a melhor política pública a ser adotada, e qual ferramenta pode auxiliar na execução dessa política.

\section{Resultados e discussões}

\subsection{Caracterização da intensidade e extensão espacial da seca}

O MSB foi implantado em julho de 2014 e teve como área piloto a região Nordeste do país. Portanto, para compor o SAB, seria necessária a inclusão do estado de Minas Gerais, que começou a integrar o SAB apenas em novembro de 2018. O processo de criação dos mapas mensais de seca fundamenta-se em três indicadores. Dois meteorológicos, um de curto prazo, denominado Indicador Padronizado de Precipitação - SPI (McKee et al., 1993), e um de longo prazo, o Indicador Padronizado de Precipitação-Evapotranspiração - SPEI 
(Vicente-Serrano et al., 2010). O primeiro tem como entrada somente dados de precipitação. Enquanto o segundo considera informações de precipitação e temperatura. $\mathrm{O}$ terceiro parâmetro abordado pelo MSB é hidrológico e corresponde ao Indicador Padronizado de Escoamento - SRI (Shukla \& Wood, 2008), que utiliza a análise de distribuição temporal diária da precipitação (Martins et al., 2015).

O Monitor Brasileiro fundamentou-se no Monitor de Secas dos Estados Unidos (USDM). Desde a sua implementação, em janeiro do ano 2000, os mapas são elaborados mensalmente e a plataforma passou a ser utilizada por gestores para a concessão de auxílios financeiros aos atingidos pelos impactos do fenômeno. Em contraponto, o monitor brasileiro só foi criado em 2014 e ainda é subtilizado pelos gestores locais. Constata-se que o Brasil só passou a preocupar-se em acompanhar a evolução das secas, tão frequentes e intensas no Nordeste do país, há pouco mais de cinco anos (Martins et al., 2016). As tipologias e os impactos esperados para cada intensidade são apresentados na Tabela 1, elaborada por Svoboda et al. (2002) e utilizada pelo USDM. A Figura 3apresenta um gráfico de áreas percentuais de seca para o Semiárido brasileiro.

Essa Figura 3 permite acompanhar a evolução espacial e de intensidades do fenômeno no decorrer de julho de 2014 a março de 2020, dos quais 2014 a 2018 são anos secos e 2019 a 2020 anos não secos. Há um pico de seca excepcional em dezembro de 2015 , entretanto a curva ameniza, voltando a ascender e registrar o clímax em janeiro de 2017, com $85 \%$ da região sob seca excepcional (S4). Em 2018, o fenômeno abranda, dando indícios do término da maior seca da história. Os anos seguintes comprovam esse fato e registram predominantemente secas

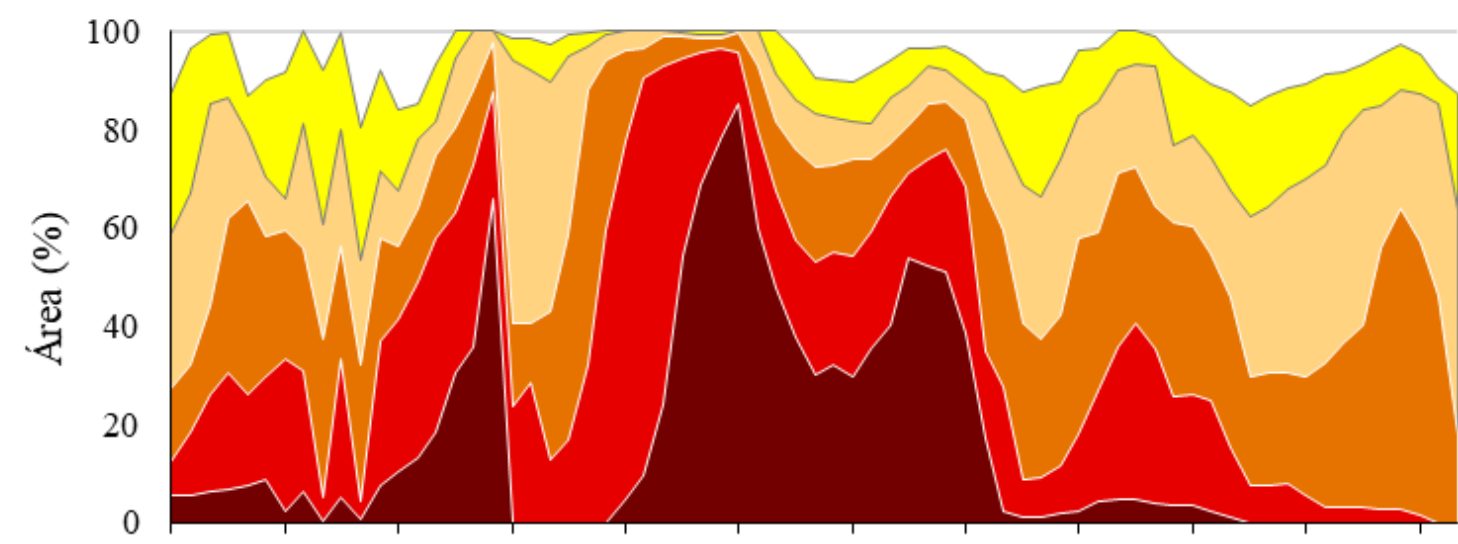

jul-14 jan-15 jul-15 jan-16 jul-16 jan-17 jul-17 jan-18 jul-18 jan-19 jul-19 jan-20

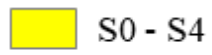

$\mathrm{S} 1-\mathrm{S} 4$

S2 - S4

$\mathrm{S} 3-\mathrm{S} 4$

S4

FIGURA 3 - Quantificação de áreas do monitor de secas: percentuais de área do semiárido brasileiro em cada intensidade de seca para o período de julho/2014 a março/2020.

FONTE: Elaborada a partir de ANA (2020). 
com possíveis impactos reversíveis, sendo estas a moderada (S1) e a grave (S2). O mês que registra o ápice de gravidade da seca é espacializado na Figura 4.

A Figura 4 demonstra quais foram as regiões do SAB que registraram intensidades mais brandas. Os municípios simbolizados são aqueles que abrigam mais de 100 mil habitantes. Apenas a faixa sudeste da Bahia (Feira de Santana, Jequié e
Vitória da Conquista), leste do $\mathrm{RN}$ e norte do CE e PI apresentaram gravidades que diferem da excepcional. Ainda assim, não são intensidades amenas de seca, pois, conforme a Tabela 1 , verifica-se que são categorias com impactos também irreversíveis. O grau de maior seriedade (S4) tem como possíveis impactos perdas agropecuárias generalizadas, além do decreto de situações de emergência devido à escassez de água.

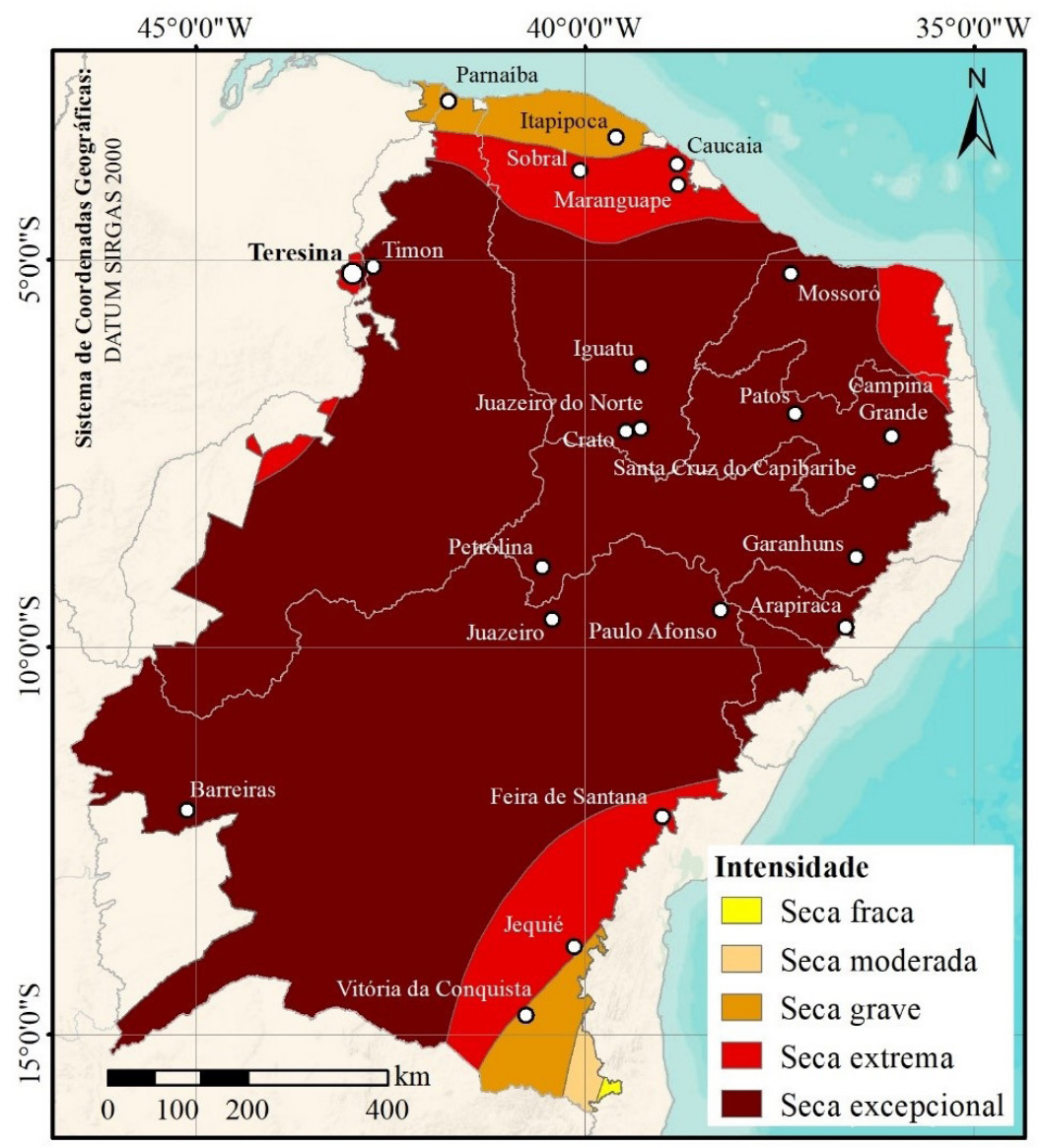

FIGURA 4 - O mês de janeiro de 2017 que registra a maior extensão espacial nas tipologias de seca mais intensas - excepcional, extrema, grave - respectivamente, para o Semiárido brasileiro.

FONTE: Elaborada a partir de IBGE (2018) e ANA (2020). 


\subsection{Variação do volume de água armazenado nos reservatórios}

Ao confrontar os meses que registraram as maiores magnitudes de seca, de acordo com o MSB, com os volumes de água acumulados nos reservatórios equivalentes dos semiáridos estaduais (Figura 5), há uma constatação da escassez hídrica, conforme os prováveis impactos enumerados na Tabela 1. Os estados do CE, RN, PB e PE registraram percentuais que estão entre os seus menores volumes de reserva hídrica para o período, com valores na marca dos $13 \%, 12 \%, 7 \%$ e $2 \%$, respectivamente.

Os quatro estados apresentam curvas de variação de volume com o mesmo delineamento no decorrer do tempo. Em 2012 (primeiro ano de seca), contavam com a maior reserva hídrica do período, entretanto o cenário foi restringindo-se até que, entre 2016 e 2018, os volumes atingiram os níveis mínimos, com muitos reservatórios atingindo o volume morto.

Segundo Dantas et al. (2020), esse comportamento de redução dos níveis de água armazenados reflete a realidade da maior parte dos açudes do $\mathrm{SAB}$, no decorrer da seca prolongada. Os reservatórios de pequeno e médio porte são os primeiros acometidos com os efeitos da seca. De acordo com Nunes (2015), isso deve-se a sua menor capacidade de armazenamento, atrelada às elevadas perdas por evaporação. Além disso, a construção descontrolada de açudes menores à montante dos reservatórios de grande porte interfere na recarga hídrica daqueles. Enquanto os açudes maiores abastecem múltiplos usos de um grande número de pessoas, os de menor tamanho são construídos para atender pequenos contingentes populacionais.
A Bahia apresentou um comportamento totalmente distinto na variação do volume de água armazenado, quando comparada aos demais estados em análise. Entre janeiro e fevereiro de 2016, houve um aporte de água de mais de $30 \%$ nos açudes do Semiárido baiano. Dessa forma, nos meses de seca mais intensa registrados pelo MSB, seus reservatórios retinham reservas de água em torno de $50 \%$ da capacidade total. Em contrapartida, no início da seca, em março de 2012, a BA registra um volume armazenado de apenas 3,9\%. A diferença, quando se compara a Bahia aos demais estados, deve-se às entradas de água provenientes de outras bacias hidrográficas à montante.

\subsection{Análise da variação nas colheitas agrícolas}

A seca iniciou-se apenas em 2012. Entretanto os anos de 2010 e 2011 (anos que demonstram a realidade da agricultura em um período não seco) são tomados para análise, pois o cálculo de variação da área colhida tem como base o ano anterior. Ou seja, para verificar se em 2012 o percentual de área aumentou ou diminui, toma-se o ano de 2011 como referência e assim sucessivamente até chegar em 2018. A Tabela 2 demonstra o resultado desse balanço para os semiáridos estaduais. $\mathrm{O}$ ano inicial da seca plurianual (2012) registra percentuais negativos para todos os estados. Paraíba, Pernambuco e Alagoas registraram uma redução de mais de $65 \%$ na sua colheita em relação ao ano anterior. Isto deve-se ao surgimento repentino do evento.

Os anos de 2013 e 2014 assinalaram pequenas variações negativas, com percentuais que não chegaram a $20 \%$ de redução. Destaca-se Pernambuco 

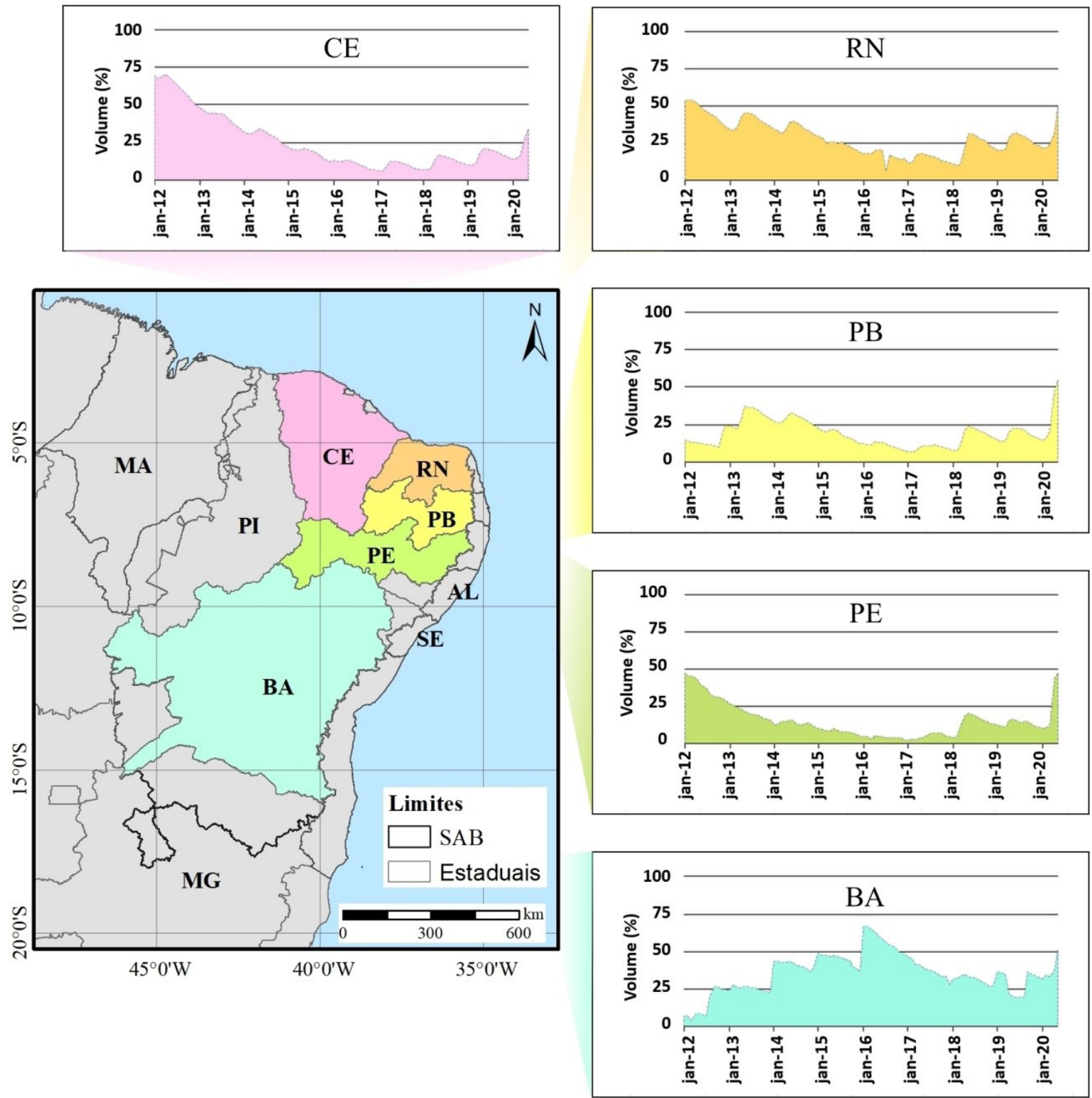

FIGURA 5 - Evolução do volume de água armazenado nas regiões semiáridas dos estados brasileiros do Ceará (CE), Rio Grande do Norte (RN), Paraíba (PB), Pernambuco (PE) e Bahia (BA), entre o período de janeiro/2012 e maio/2020.

FONTE: Elaborada a partir de IBGE (2018) e INSA (2020). 
TABELA 2 - Percentuais que indicam se houve aumento ou redução na área colhida de lavouras temporárias e permanentes para os Semiáridos dos estados brasileiros.

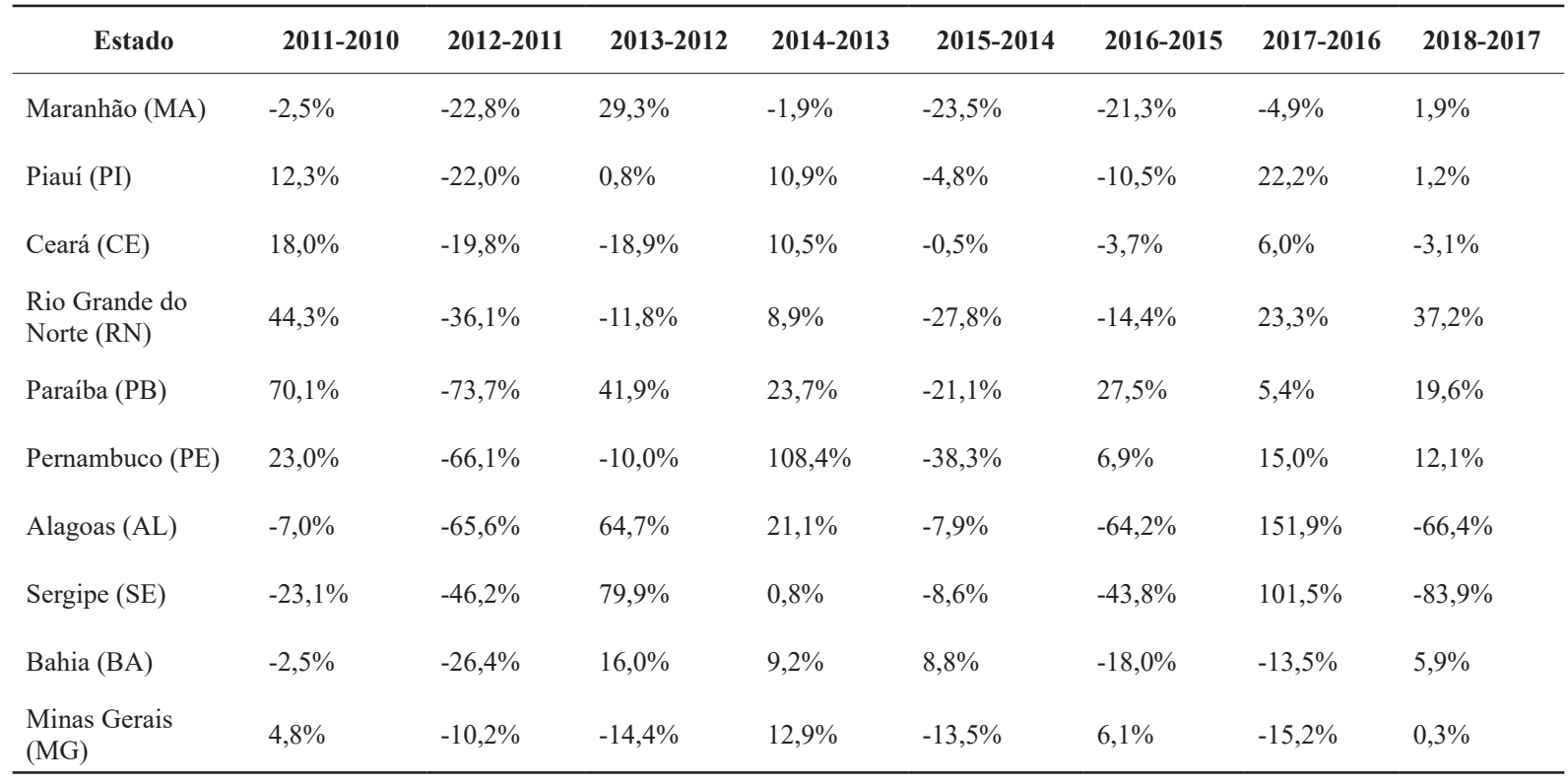

FONTE: Elaborada a partir de IBGE (2019).

que, em 2014, elevou sua colheita em mais de 100\% em relação ao ano anterior. Alagoas e Sergipe, que registraram quedas bruscas em suas colheitas em 2012 e 2016, recuperam-se em 2017 com um aumento de $151 \%$ e $101 \%$, respectivamente.

Diferente das variações do volume de água armazenado nos reservatórios, disponibilizadas no portal Olho N'água, as quais retrataram cenários de crise hídrica e colapso no abastecimento, no mesmo período em que as secas estavam em alta severidade, a variação dos percentuais de área colhida de lavouras temporárias e permanentes não obedeceram a mesma tendência.

\subsection{Medidas estruturais e não-estruturais adotadas}

A pesquisa MUNIC do IBGE (2017) permite identificar quais são as medidas adotadas pelos municípios para conviver com o quadriênio 20132016 de secas no Brasil. Quando questionados quanto à construção de açudes (Figura 6a), mais de $41 \%$ dos gestores municipais do $\mathrm{SAB}$ confirmaram obras hidráulicas desse tipo. Segundo Campos (2015), a política de construção de reservatórios manifesta-se como a primeira tentativa adotada na região Nordeste para sanar os efeitos da seca, a partir de 1877. Essa perspectiva continuou até meados do século XX, quando a estrutura hidráulica já era significativa e, mesmo assim, os impactos da 

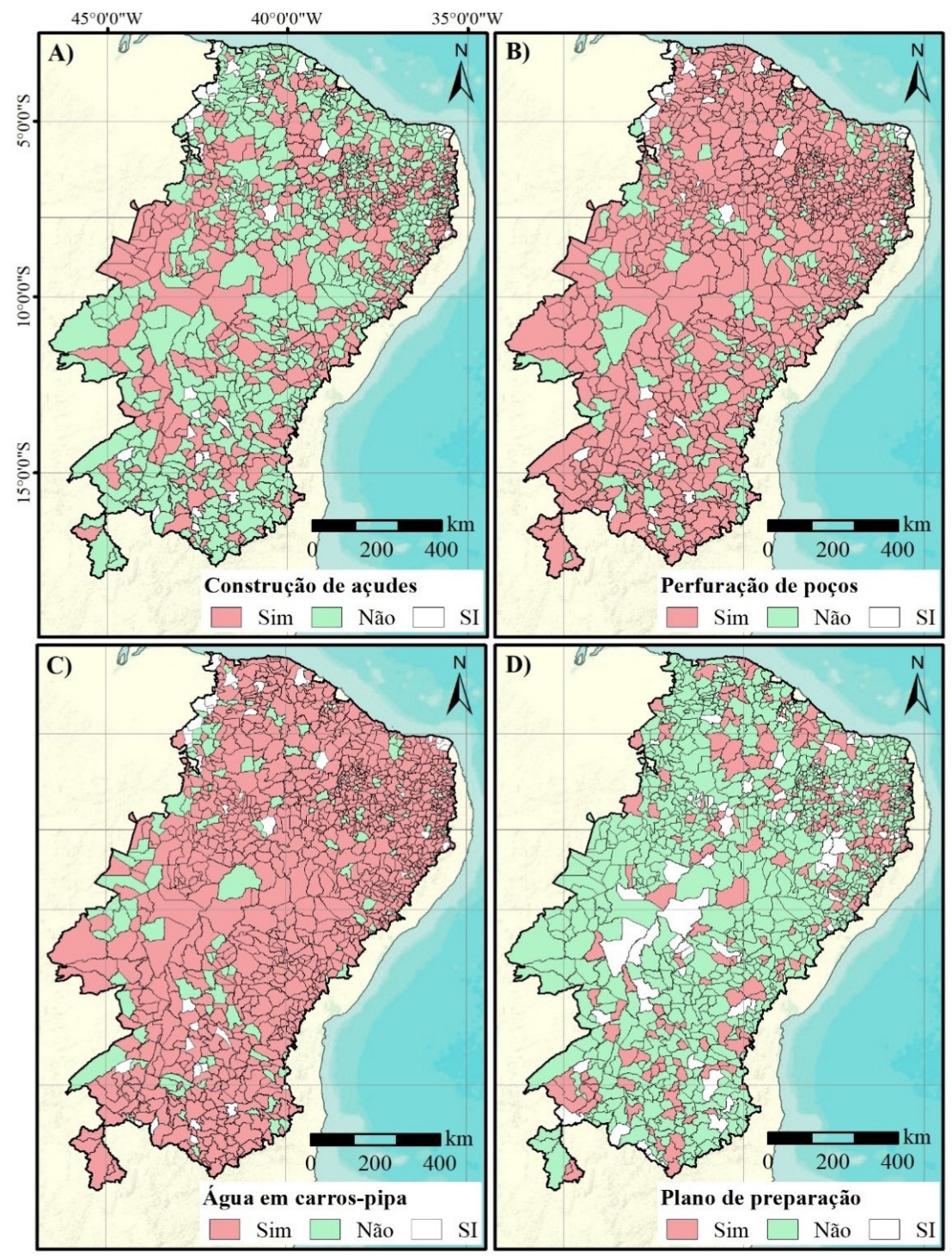

FIGURA 6 - Espacialização de informações da Pesquisa de Informações Básicas Municipais referente às medidas adotadas para lidar com a seca entre 2013 e 2016: a) construção de cisternas; b) perfuração de poços; c) distribuição de água por meio de carros-pipa; d) existência de plano para convivência com a seca.

FONTE: Elaborada a partir de IBGE $(2017 ; 2018)$.

LEGENDA: SI= sem informação. 
escassez de chuvas ainda se manifestavam bastante rigorosos. Embora o enfoque das políticas públicas de seca tenha passado por evoluções no decorrer dos anos, constata-se que a construção de açudes é uma medida ainda fortemente adotada.

Outra medida estrutural bastante disseminada no $\mathrm{SAB}$, para convivência com as secas recorrentes, é a perfuração de poços artesianos. Um total de $77,5 \%$ dos municípios da região contou com esse artifício (Figura 6b), na tentativa de mitigar os impactos da escassez hídrica. Segundo Dias et al. (2018), esse alto percentual deve-se à facilidade de execução do processo e, principalmente, da proximidade à fonte de água. Entretanto os autores apontam que grande parte dos poços são perfurados e explorados clandestinamente, sem a solicitação de outorgas de direito de uso da água, conforme preconiza a Lei no 9.433/1997 (Brasil, 1997).

Por sua vez, a distribuição de água por meio de carros-pipa é uma medida adotada em situações de emergência, ou seja, quando a seca atinge níveis excepcionais. Mais de $86 \%$ dos municípios do $\mathrm{SAB}$ chegaram a essas circunstâncias de emergência, conforme mostra a Figura 6c. Comprova-se que, entre as medidas estruturais especializadas, os carros-pipa constituem a mais utilizada. Todavia, segundo Duque (2008), os programas de assistência emergencial, entre os quais está a distribuição de água por carros-pipa, amenizam os efeitos da seca, entretanto não resolvem a situação. Ainda segundo a autora, a solução é estabelecer um modelo de gestão que permita "conviver com as secas e não lutar contra".

Quanto à análise de medidas não estruturais, um indicador de grande relevância abordado na pesquisa MUNIC refere-se à existência de plano de contingência ou preparação para a seca. Pouco mais de $20 \%$ dos municípios do SAB afirmaram dispor desse planejamento (Figura 6d). Indica um percentual considerável, tendo em vista que nem os estados beneficiam-se de tal instrumento. O Ceará, dentre os estados do Nordeste, é o único que apresenta um plano. Entretanto sua elaboração se deu apenas em 2015, quando a seca plurianual já tinha avançado consideravelmente. Além disso, o conteúdo abordado volta-se apenas para ações estruturais e emergenciais (Ceará, 2015).

Uma série de políticas públicas que beneficiam as pessoas em situação de pobreza foram implementadas pelo governo federal nesse início de século. Tanto os auxílios para o combate à pobreza extrema quanto para minimizar os efeitos das secas intensas. Alguns exemplos são o P1MC, o Programa Uma Terra e Duas Águas (P1+2) e o Garantia-Safra. O $\mathrm{P} 1 \mathrm{MC}$ e o $\mathrm{P} 1+2$ são iniciativas da Articulação no Semiárido Brasileiro (ASA), a qual atua sob um intenso processo participativo da sociedade civil na implantação de tecnologias sociais para convivência no SAB (ASA Brasil, 2020).

\subsection{Políticas públicas para gestão proativa de secas}

As discussões permitem corroborar que os tomadores de decisão reagem diante da seca já identificada, e não adotam posturas proativas baseadas em planejamento e gestão de risco. Nesse sentido, as políticas públicas observadas nessas posturas reativas, em sua grande maioria, tornam-se soluções temporárias e de baixa eficiência para a mitigação dos impactos. Essa gestão ineficaz e reativa das secas explicita a fragilidade institucional do poder público que, por não ter entendimento sobre onde a 
gestão de secas insere-se na administração pública aliado à fragilidade dos órgãos responsáveis, gera um fenômeno conhecido como "indústria da seca" (Silva, 2006). Esse termo, de acordo com Pereira \& Silva (2020), consiste no "uso da seca como estratégia de exploração da miséria pelas oligarquias nordestinas".

Uma gestão proativa deveria procurar atender sobretudo as populações mais vulneráveis que habitam áreas em seca moderada e extrema, a fim de minimizar os efeitos das secas plurianuais, que tem se tornado mais intensas já no início deste século. Além disso, ações proativas devem ser voltadas para uma gestão participativa que identifica as reais necessidades da população a fim de implantar as tecnologias com a colaboração da sociedade civil diretamente beneficiada que habita no $\mathrm{SAB}$, o que advém de ações de planejamento e preparação.

A discussão global da vulnerabilidade à seca reduz os riscos associados a sua ocorrência por meio da introdução de planejamento para melhorar as capacidades operacionais (ou seja, monitoramento do clima e do abastecimento de água, construção de capacidade institucional) e medidas de mitigação que visam reduzir impactos da seca (Engle et al, 2016; Brito et al, 2021).

De acordo com Wilhite et al. (2014), há três tipos de políticas de seca que são utilizadas para a gestão do fenômeno, que são:

i. intervenção governamental ou não governamental pós-impacto, que consiste na concessão de assistência emergencial (financeira, água, comida) à população impactada pelos efeitos da seca;

ii. programas governamentais de pré-impacto que objetivam a redução das vulnerabilidades e dos impactos da seca, por meio de medidas de mitigação;

iii. desenvolvimento e implementação de planos e políticas de preparação, que devem ser desenvolvidos antes da ocorrência da seca e mantidos nos anos em que o fenômeno não ocorre.

O modelo brasileiro de políticas de seca baseia-se na intervenção governamental. Entretanto é um sistema reativo de gestão que não tem demonstrado ser eficiente para convivência com o fenômeno. O planejamento deve acontecer nas diversas escalas (macro - nacional-, a micro - pequena propriedade rural) tomando como base a criação e implementação de planos de preparação, conforme apontado por Wilhite et al. (2014). Um mecanismo essencial para nortear a elaboração desses planos, consiste no processo de planejamento em 10 etapas, desenvolvido por Wilhite (1991) e posteriormente aprimorado por Wilhite et al. (2000; 2005), e as etapas são listadas a seguir:

1. Nomear uma força-tarefa para a gestão da seca.

2. Declarar o propósito e os objetivos do plano de preparação.

3. Buscar a participação das partes interessadas e resolver os conflitos.

4. Inventariar recursos e identificar os grupos em risco.

5. Desenvolver a estrutura organizacional e preparar o plano para a seca.

6. Identificar necessidades de pesquisa e preencher lacunas institucionais.

7. Integrar ciência e política.

8. Divulgar o plano para a seca, conscientizar o público. 


\section{Ensinar as pessoas sobre a seca.}

10. Avaliar e revisar o plano de preparação para a seca.

Primeiramente é necessária a seleção de pessoas capacitadas para compor a força-tarefa de elaboração do plano de seca. Essa equipe deve definir os objetivos, buscar elaborar o documento mediante uma gestão participativa, na busca por resolver os conflitos originados com o advento do evento de seca. Para isso, estudos que analisem as áreas mais vulneráveis e de maior fragilidade diante da ocorrência do fenômeno são imprescindíveis. A equipe deve ser multidisciplinar e alinhar todo o desenvolvimento do plano na aplicabilidade prática, que deve ser testada antes do advento da seca. Por fim, a conscientização da sociedade civil tem que acontecer, além de revisões periódicas ao plano de preparação.

\section{Conclusões}

As secas, embora caracterizadas como um desastre natural, são tão frequentes na região semiárida brasileira que não são mais referidas como um fenômeno a se combater, e sim a se conviver. Trata-se de uma temática relevante para as discussões que concernem aos múltiplos usos dos recursos hídricos e aos demais recursos naturais, à agropecuária e à sociedade, uma vez que os efeitos das secas marcam desdobramentos sociais que atingem sobretudo a parte mais vulnerável da população.

O Semiárido brasileiro, apesar da experiência de séculos em secas recorrentes, ainda não compreendeu como conviver com o fenômeno. Embora os eventos estejam mais duradouros e intensos, as medidas prioritárias para lidar com os efeitos negativos continuam sendo, predominantemente, de cunho estrutural. Como afirma Campos (2015), o SAB é naturalmente vulnerável à seca, mesmo quando as densidades populacionais eram baixas, ainda no início da colonização.

As condições naturais do SAB compreendem baixos índices pluviométricos, elevadas taxas de evaporação, solos que desfavorecem a exploração de recursos hídricos subterrâneos. Diante disso, políticas públicas adequadas precisam ser implantadas, sobretudo no que se refere às populações mais vulneráveis, residentes em áreas rurais. Em contrapartida, a seca plurianual 2012-2018 também atingiu as cidades, que tiveram os seus sistemas de abastecimento de água em colapso, com reservatórios atingindo níveis de volume morto.

Visto que esse tipo de desastre natural é reincidente, e que a construção de infraestrutura hídrica não tem sido suficiente para lidar com as consequências da escassez hídrica, resta adotar uma perspectiva pautada no planejamento e na preparação para as secas. Todos os estados norte-americanos possuem seus Planos Estaduais de preparação, além de um Sistema de Monitoramento e Alerta Precoce utilizado pelos gestores na tomada de decisões. Enquanto isso, no Brasil, as medidas de resposta só entram em ação quando os impactos já provocaram danos aos mais diversos setores.

Diante da caracterização espaço-temporal e de severidade da seca, sob a perspectiva do MSB, constata-se que, embora recente, a plataforma representa um avanço no panorama de preparação aos eventos futuros. Juntamente com o Olho N'água, que permite monitorar a evolução dos volumes de água armazenados. Tais seguimentos, em consonância com a elaboração de planos estaduais que 
dinamizem o ciclo de gestão à uma mudança de paradigma, voltada ao gerenciamento proativo do fenômeno, tem todo um embasamento que poderia estimular uma mudança na forma como os gestores lidam com o advento das frequentes secas no sertão nordestino.

\section{Referências}

Alvalá, R. C. S.; Cunha, A. P. M. A.; Brito, S. S. B.; Seluchi, M. E.; Marengo, J. A.; Moraes, O. L. L.; Carvalho, M. A. Drought monitoring in the Brazilian Semiarid region. Earth Sciences, 91(1), e20170209, 2019. doi: 10.1590/00013765201720170209

AMS - American Meteorological Society. Drought, 2013. Disponível em: $<$ https://www.ametsoc.org/index.cfm/ams/ about-ams/ams-statements/statements-of-the-ams-in-force/ drought/?>. Acesso em: fev. 2020.

ANA - Agência Nacional de Águas e Saneamento Básico. Plano Nacional de Segurança Hídrica, 2019. Disponível em: <https://arquivos.ana.gov.br/pnsh/pnsh.pdf >. Acesso em: mar. 2020.

ANA - Agência Nacional de Águas e Saneamento Básico. Sistema de Acompanhamento de Reservatórios, 2021. Disponível em: <https://www.ana.gov.br/sar/>. Acesso em: out. 2021.

ANA - Agência Nacional de Águas e Saneamento Básico. Monitor de secas do Brasil, 2020. Disponível em: <http:// monitordesecas.ana.gov.br/dados-sig? $a n o=2020>$. Acesso em: abr. 2020.

ASA Brasil-Articulação no Semiárido Brasileiro. Mapa de tecnologias, 2020. Disponível em: <https://www.asabrasil. org.br/mapatecnologias/>. Acesso em: abr. 2020.

Brasil. Lei $n^{\circ}$ 9.433, de 8 de janeiro de 1997. Institui a Política Nacional de Recursos Hídricos, cria o Sistema Nacional de Gerenciamento de Recursos Hídricos, regulamenta o inciso XIX do art. 21 da Constituição Federal, e altera $\mathrm{o}$ art. $1^{\circ}$ da Lei ${ }^{\circ} 8.001$, de 13 de março de 1990, que modificou a Lei $\mathrm{n}^{\circ} 7.990$, de 28 de dezembro de 1989.
Brasília: DOU de 9/1/1997.

Brito, S. S. B.; Cunha, A. P. M. A.; Cunningham, C. C.; Alvalá, R. C.; Marengo, J. A.; Carvalho, M. A. Frequency, duration and severity of drought in the Semiarid Northeast Brazil region. International Journal of Climatology, 38(2), 517-529, 2018. doi: 10.1002/joc.5225

Brito, Y. M. A. de; Rufino, I. A. A.; Braga, C. F. C.; Mulligan, $\mathrm{K}$. The Brazilian drought monitoring in a multi-annual perspective. Environmental Monitoringand Assessment, 193, 31, 2021. doi: 10.1007/s10661-020-08839-5

Campos, J. N. B. Secas e políticas públicas no semiárido: ideias, pensadores e períodos. Sociedade e Ambiente Estudos Avançados, 28(82), 65-88, 2014. doi: 10.1590/ S0103-40142014000300005

Campos, J. N. B. Paradigms and public policies on drought in Northeast Brazil: a historical perspective. Environmental Management, 55, 1052-1063, 2015. doi: 10.1007/s00267015-0444-x

Ceará - Governo do Estado. Plano Estadual de Convivência com a Seca: ações emergenciais e estruturantes, 2015. Disponível em: <http://www.mpce.mp.br/wp-content/uploads/2016/05/Plano_Convivencia_com_a_ Seca_02_03_2015-1.pdf>. Acesso em: jan. 2020.

Cunha, A. P. M. A.; Zeri, M.; Leal, K. D.; Costa, L.; Cuartas, L. A.; Marengo, J. A.; Tomasella, J.; Vieira, R. M.; Barbosa, A. A.; Cunningham, C.; Garcia, J. V. C.; Broedel, E.; Alvalá, R.; Ribeiro-Neto, G. Extreme Drought Events over Brazil from 2011 to 2019. Atmosphere, 10(11), 642, 2019. doi: 10.3390/atmos 10110642

Dantas, J. C.; Silva, R. M. da; Santos, C. A. G. Drought impacts, social organization, and public policies in northeastern Brazil: a case study of the upper Paraíba River basin. Environmental Monitoringand Assessment, 192, 317, 2020. doi: 10.1007/s10661-020-8219-0

Dias, A. C. H.; Santiago, M. C.; Vieira, B. A.; Nogueira, L. Perfuração indiscriminada de poços em Iracema/CE: um estudo sobre o paradoxo da atual crise hídrica. Águas Subterrâneas, 32(3), 2018. doi: 10.14295/ras.v32i3.29167

Duque, G. "Conviver com a seca": contribuição da Articulação do Semi-Árido/ASA para o desenvolvimento sus- 
tentável. Desenvolvimento e Meio Ambiente, 17, 133-140, 2008. doi: 10.5380/dma.v17i0.13417

ESRI. ArcGIS Desktop versão10.7.1. Redlands: Environmental Systems Research Institute, 2019.

Engle, N.; De Nys, E.; Magalhães, A. R.; Redwood III, J. Planejamento para a próxima seca e preparação do caminho para a resiliência às mudanças climáticas. In: De Nys, E.; Engle, N. L.; Magalhães, A. R. (Orgs.). Secas no Brasil: Política e gestão proativas. Brasília: Centro de Gestão e Estudos Estratégicos; Banco Mundial, p. 125-132, 2016.

IBGE - Instituto Brasileiro de Geografia e Estatística. Pesquisa de Informações Básicas Municipais - MUNIC, 2017. Disponível em: $<$ https://www.ibge.gov.br/estatisticas/ sociais/saude/10586-pesquisa-de-informacoes-basicas-municipais.html $?=\& \mathrm{t}=$ resultados $>$. Acesso em: jan. 2020.

IBGE - Instituto Brasileiro de Geografia e Estatística. Downloads - Geociências, 2018. Disponível em: <https:// www.ibge.gov.br/geociencias/downloads-geociencias. html>. Acesso em: abr. 2020.

IBGE - Instituto Brasileiro de Geografia e Estatística. Pesquisa Agrícola Municipal - PAM, 2019. Disponível em: $<\mathrm{https}$ ///sidra.ibge.gov.br/pesquisa/pam/tabelas > Acesso em: abr. 2020.

INSA - Instituto Nacional do Semiárido. Olho N'água, 2020. Disponível em: <https://olhonagua.insa.gov.br/\#!/>. Acesso em: maio 2020.

Magalhães, A. R. Vida e seca no Brasil. In: De Nys, E. de; Engle, N. L.; Magalhães, A. R. (Orgs.). Secas no Brasil: Política e gestão proativas. Brasília: Centro de Gestão e Estudos Estratégicos; Banco Mundial, p. 19-35, 2016.

Maisonnave, F.; Prado, A. Nordeste: Seca histórica já dura seis anos e ameaça tornar-se regra no semiárido. Folha de São Paulo, 24 de abr., 2018. Disponível em: <https://arte. folha.uol.com.br/ciencia/2018/crise-do-clima/nordeste/ seca-historica-ja-dura-seis-anos-e-ameaca-tornar-se-regra-no-semiarido/>. Acesso em: abr. 2020.

Marengo, J. A., Bernasconi, M. Regional differences in aridity/drought conditions over Northeast Brazil: present state and future projections. Climatic Change, 129, 103-115, 2015. doi: 10.1007/s10584-014-1310-1
Martins, E. S. P. R.; De Nys, E.; Molejón, C.; Biazeto, B.; Silva, R. F. V.; Engle, N. Monitor de Secas do Nordeste, em busca de um novo paradigma para a gestão de secas. Brasília: Banco Mundial, 1. ed., 2015. Disponível em: $<$ https://documents1.worldbank.org/curated/en/607701468197373119/ pdf/106302-PORTUGUESE-PUB-P146301-ADD-SERIES-AND-ISBN-PUBLIC-Aguas-Brasil-no-10.pdf>. Acesso em: dez. 2019.

Martins, E. S. P. R.; Quintana, C. M.; Dias, M.A. F. S.; Silva, R. F. V.; Biazeto, B.; Forattini, G. D.; Martins, J. C. O caso técnico e institucional - Monitor de Secas do Nordeste como âncora e facilitador da colaboração. In: De Nys, E.; Engle, N. L.; Magalhães, A. R. (Orgs.). Secas no Brasil: Política e gestão proativas. Brasília: Centro de Gestão e Estudos Estratégicos; Banco Mundial, p. 61-72, 2016.

Mckee, T. B.; Doesken, N. J.; Kleist, J. The relationship of drought frequency and duration to time scales. In: Eighth Conference on Applied Climatology. Anaheim, 17-22 de jan., 1993.

Mishra, A. K.; Singh, V. P. A review of drought concepts. Journal of Hydrology, 391(1-2), 202-216, 2010. doi: 10.1016/j.jhydrol.2010.07.012

NDMC - National Drought Mitigation Center. United States drought monitor, 2020. Disponível em: $<$ https://droughtmonitor.unl.edu/>. Acesso em: mar. 2020.

Nunes, T. H. C. A gestão do reservatório Epitácio Pessoa e regras de operação otimizadas. Campina Grande, Dissertação (Mestrado em Engenharia Civil e Ambiental) - UFCG, 2015.

Nunes, T. H. C.; Galvão, C. de O.; Rêgo, J. C. Rule curve for seasonal increasing of water concessions in reservoirs with low regularized discharges. Revista Brasileira de Recursos Hidricos, 21(3), 493-501, 2016. doi: 10.1590/23180331.011615146

Pereira, J. W. G.; Silva, C. N. M. da. Barragem Poço de Varas: uma proposta política centenária. Desenvolvimento e Meio Ambiente, 55, 238-261, 2020. doi: 10.5380/dma. v55i0.73622

Shukla, S., Wood. A. W. Use of a standardized runoff index for characterizing hydrologic drought. Geophysical Research Letters, 35(2), L02405, 2008. doi: 10.1029/2007GL032487 
Silva, N. M. da; Andrade, A. J. P. de; Souza, C. R. de. O sertanejo e as experiências de inverno no Seridó Potiguar. Desenvolvimento e Meio Ambiente, 27, 87-107, 2013. doi: 10.5380/dma.v27i0.29829

Silva, R. M. A. Entre o combate à seca e a convivência com o semiárido: transições paradigmáticas e sustentabilidade do desenvolvimento. Brasília, Tese (Doutorado em Desenvolvimento Sustentável) - UnB, 2006.

SUDENE - Superintendência de Desenvolvimento do Nordeste. Resolução no 107/2017, de 27 de julho de 2017. Estabelece critérios técnicos e científicos para delimitação do Semiárido Brasileiro e procedimentos para revisão de sua abrangência. Brasília: DOU de 13/9/2017.

Svoboda, M.; LeComte, D.; Hayes, M.; Heim, R.; Gleason, K.; Angel, J.; Rippey, B.; Tinker, R.; Palecki, M.; Stookbury, D.; Miskus, D.; Stephens, S. The drought monitor. Bulletin of the American Meteorological Society, 83, 1181-1190, 2002. doi: 10.1175/1520-0477-83.8.1181

Vicente-Serrano, S. M.; Beguería, S.; López-Moreno, J. I. A multiscalar drought index sensitive to global warming: the standardized precipitation evapotranspiration index. Journal of Climate, 23(7), 1696-1718, 2010. doi: 10.1175/2009JCLI2909.1

Wilhite, D. A. Drought planning: A Process for State Government. Water Resources Bulletin, 27(1), 29-38, 1991. Disponível em: https://digitalcommons.unl.edu/cgi/viewcontent.cgi? article $=1023 \&$ context $=$ droughtfacpub
Wilhite, D. A. Integrated drought management: moving from managing disasters to managing risk in the Mediterranean region. Euro-Mediterranean Journal for Environmental Integration, 4, 42, 2019. doi: 10.1007/s41207-019-0131-z

Wilhite, D. A.; Glantz, M. H. Understanding the drought phenomenon: The Role of Definitions. Water International, 10(3), 111-120, 1985. Disponível em: http://www.esalq.usp. br/lepse/imgs/conteudo_thumb/Understanding-the-Drought-Phenomenon-The-Role-of-Definitions.pdf

Wilhite, D. A.; Hayes, M. J.; Knutson, C. L. Drought preparedness planning: building institutional capacity. In: Wilhite, D. A. (Ed.). Drought and water crises: science, technology, and management issues. Boca Raton: CRC Press, p. 93-135, 2005.

Wilhite, D. A.; Hayes, M. J.; Knutson, C.; Smith, K. H. Planning for drought: moving from crisis to risk management. Journal of the American Water Resources Association, 36(4), 697-710, 2000. doi: 10.1111/j.1752-1688.2000. tb04299.x

Wilhite, D. A.; Sivakumar, M. V. K.; Pulwarty, R. Managing drought risk in a changing climate: the role of national drought policy. Weather and Climate Extremes, 3, 4-13, 2014. doi: 10.1016/j.wace.2014.01.002 